\title{
Tecendo os fios entre educação e saúde: avaliação do Programa da Residência Multiprofissional em Saúde
}

\author{
Soraya Diniz Rosa \\ Roseli Esquerdo Lopes
}

Resumo: Neste estudo objetivou-se refletir sobre a educação superior brasileira, especificamente a formação de profissionais da saúde no Brasil, por meio da avaliação de um Programa de Residência Multiprofissional em Saúde, a partir da análise das perspectivas que se abrem no processo de construção e implementação de políticas públicas, apresentadas, atualmente, para a formação superior na área. Esse Programa do Ministério da Saúde, em parceria com o Ministério da Educação, viabiliza-se por meio de um curso de pós-graduação lato-sensu e pretende capacitar os profissionais da saúde, com exceção da área médica, para enfrentarem as dificuldades na organização dos serviços embasados na lógica do Sistema Único de Saúde (SUS). Tomou-se como estudo empírico um programa implantado, no ano de 2006, por uma universidade pública, localizada no interior do estado de São Paulo, numa proposta de cogestão institucional com a Secretaria Municipal de Saúde. Esta pesquisa, portanto, caracteriza-se como um estudo focal e, lançando-se mão de uma perspectiva sócio histórica, foram analisados documentos no campo da educação e da saúde e, posteriormente, as narrativas dos sujeitos envolvidos no Programa, especialmente os residentes. A análise dos resultados alcançados permitiu afirmar a importância da formulação e execução de políticas para a formação de recursos humanos, assim como a prioridade em se produzir mudanças no modelo de atenção à saúde; entretanto, este Programa esteve condicionado à oferta de um campo de trabalho precarizado para os residentes, frente à necessidade da gestão de estruturar a rede de serviços públicos do município.

Palavras-chave: Avaliação. Capacitação profissional. Residência multiprofissional em saúde. Pós-graduação lato sensu. Educação superior.

\section{Weaving the wires between education and health: program evaluation of residence in health multiprofessional}

Abstract: The purpose of this study is to reflect on the Brazilian higher education, specifically the training of health professionals in Brazil, through the evaluation of a Multidisciplinary Residency Program in Health, from the analysis of the opportunities opening up in the construction process and implementation of public policies, submitted today for higher education in the area. This program enables by means of a post-graduation-sense and intends to train health professionals, with the exception of the medical field, to face the difficulties in the organization of services grounded in the logic of the Unified Health System (SUS). It became an implanted empirical study program, in 2006, by a public university, located in the state of São Paulo, in a proposal for institutional congestion with the Municipal Health. This research, therefore, characterized as a by a focus on study and, observing a socio historical perspective, documents were analyzed in the field of education and health and, subsequently, the narratives of those involved in the program, especially the residents. The analysis of the results obtained allowed to affirm the importance of formulating and implementing policies for the training of human resources, as well as the priority in producing changes in the health care model. However, this program was limited to the offering of a labor camp precarious for residents front the need for management to structure the network of public services in the municipality.

Key words: Evaluation. Professional training. Multidisciplinary residency in health. Lato Sensu postgraduate. Higher education. 


\section{Introdução}

O Programa da Residência Multiprofissional em Saúde assume no âmbito da educação superior brasileira a possibilidade de capacitar os profissionais da área da saúde ${ }^{1}$ e áreas afins ${ }^{2}$, com exceção da medicina, para a atuação no Sistema Único de Saúde (SUS) e se viabiliza por meio de um curso de pós-graduação lato sensu. Esse Programa, lançado pelo Ministério da Saúde em parceria com o Ministério da Educação, no ano de 2005, foi apresentado como estratégia de reorientação da Atenção Básica de Saúde (ABS) para a implantação e/ou reorganização dos serviços públicos, através da cooperação técnica para a formação e o desenvolvimento de recursos humanos nesse setor (BRASIL, 2005).

Este artigo traz parte dos resultados de uma pesquisa, que se caracterizou como um estudo empírico sobre a implantação e desenvolvimento de um Programa da Residência Multiprofissional em Saúde, cujo objetivo geral foi o de avaliar as perspectivas que se abrem no processo de construção e implementação de políticas públicas para capacitação de profissionais da saúde neste nível de formação.

A justificativa do tema se deu pela importância da implantação de programas de formação pós-graduada em saúde, especialmente para as categorias não médicas, cujos profissionais compõem as equipes de saúde e têm sido pouco valorizados no sentido da capacitação profissional. Além da necessidade de avaliação das ações indutoras para a capacitação de pessoal, uma vez que durante a implantação do SUS não se conseguiu elaborar uma efetiva política de recursos humanos e, como consequência, se permitiu que os trabalhadores não tivessem perspectiva de carreira profissional; como, igualmente, se autorizou que a renovação e expansão de novos profissionais se dessem por meio da precarização do trabalho, justificada fortemente pelas limitações definidas pela Lei de Responsabilidade Fiscal (MACHADO, 2010), engessando a criação de novos cargos e a regularização do número de profissionais no campo da saúde (BARBOSA, 2010).

Nesse contexto, a precarização da gestão de recursos humanos na saúde incorre na dificuldade de organização do serviço e, como consequência, há uma desqualificação da rede de atenção em saúde. O Relatório de Gestão da Secretaria de Assistência à Saúde (1998-2001) apontou como um dos obstáculos para a mudança do modelo de atenção à saúde o fato dos profissionais não estarem preparados para este trabalho. O Manual Técnico do Departamento de

1 De acordo com a Resolução do Conselho Nacional de Saúde, no 287, de 08 de outubro de 1998, as categorias profissionais que atuam na área de saúde e que possuem formação de nível superior, são: Biomedicina, Ciências Biológicas, Educação Física, Enfermagem, Farmácia, Fisioterapia, Fonoaudiologia, Medicina, Medicina Veterinária, Nutrição, Odontologia, Psicologia, Serviço Social e Terapia Ocupacional (BRASIL, 1998).

2 Definidas como: Educação Física, Psicologia e Serviço Social. 
Gestão da Educação na Saúde (SGTES) descreveu que a maioria das secretarias estaduais e municipais de saúde não possui planos de cargos e carreiras e/ou estes estão desatualizados (BRASIL, 2006).

Há a necessidade de se lidar com a emergência na produção de mudanças no modelo de atenção à saúde no Brasil, pois vários fatores concorrem para a sua mercantilização. Os serviços públicos constantemente são criticados pelos usuários, pela mídia, pela academia e por diversas instituições, focando a ineficiência dos resultados e a desqualificação dos profissionais.

Desse modo, a referida pesquisa pretendeu colocar em evidência esta modalidade de especialização, com a finalidade de refletir sobre a dimensão política que o Programa da Residência Multiprofissional em Saúde assume tanto no âmbito da educação superior quanto da saúde pública no Brasil, diante da necessidade de qualificação da assistência prestada pela ABS e do que prevê o SUS (ROSA, 2012).

\section{Algumas considerações sobre as políticas públicas de educação e a formação profissional em saúde}

Ao se considerar que o debate sobre a formação profissional está atrelado ao processo de formação acadêmica, compreende-se o engendramento que se estabelece entre as condições estruturais da base econômica da sociedade, as ideias pedagógicas e as políticas adotadas pelo Estado na construção da educação. Desta forma, a análise que se faz dessa correlação se justifica pela dimensão social que a educação assume no âmbito da concepção marxista de mundo. Nesta perspectiva, considera-se que o conhecimento acumulado pela humanidade e que se constitui em condições superestruturais está estreitamente ligado ao movimento do capital e do trabalho.

As transformações ocorridas no mundo capitalista estabeleceram uma sociedade em que as relações sociais vigentes foram fundamentadas na apropriação privada dos meios de produção (MARX, 1983), incluindo-se nessa apropriação a educação, concebida num modelo "produtivista" (SAVIANI, 2002), o qual dificultou as "objetivações produzidas historicamente em relação à cultura humana" (DUARTE, 2008, p. 37).

Portanto, se no Brasil, na década de 1970, houve uma conquista obtida pelo movimento da classe trabalhadora que exigia escola para seus filhos, a expansão da educação básica se deu com a precarização de seus recursos humanos e materiais. Assim, a positividade do acesso à educação foi objetivada pela necessidade política do país adentrar na fase do "Brasil potência", trazendo dentre outras consequências a pauperização da educação básica, com o abandono da escola pública por parte dos filhos das classes burguesas, que buscaram uma educação que se mantinha acessível para a elite (BITTAR, 2007). 
Olhando-se para a história da educação no Brasil, pode-se concluir que esta esteve sempre atrelada a uma perspectiva de manutenção de um status quo que não lida com uma profunda desigualdade social, mesmo dentro do que foi possível mudar em outras sociedades igualmente capitalistas (BITTAR, 2007); para Nosella e Buffa (1998) a dualidade 'escola secundária/superior para as elites' e a 'primária/profissional para trabalhadores' persiste em nosso país. A crise profunda pela qual a escola passa hoje é, também, reflexo de sua incapacidade pedagógica de formular currículos e métodos que incorporem o trabalho produtivo sem renunciar à dimensão desinteressada e universal da cultura clássica (NOSELLA; BUFFA, 2002).

Relativamente, o nível sempre privilegiado da educação foi o ensino superior, pois numa sociedade sem uma cultura da educação básica, a ideia da ascensão profissional e da garantia de um status obtido pelo título foi, entre nós, definida por ele.

As políticas educacionais reforçam, na maioria das vezes, esse privilégio, tanto que, no ano 2000, o investimento público direto por aluno na educação superior foi de $129,6 \%$, reduzindo-se a $92,5 \%$, no ano de 2007 . Em contrapartida, nesse mesmo período, o investimento no ensino fundamental não chegou a $12 \%$ e, em 2007, variou entre 17 a 19\%. Nessa perspectiva, conclui-se que $70 \%$ do financiamento público estiveram naquele nível de ensino (FIGUEIREDO, 2010).

Por outro lado, o acesso à educação superior tem gerado uma demanda de estudantes com maiores carências acadêmicas, levando a uma grande heterogeneidade na qualidade da formação entre as Instituições de Ensino Superior - IES (BITTAR, 2007; SAVIANI, 2008). Além disso, os cursos de pós-graduação que deveriam capacitar o profissional para as mudanças operadas na própria profissão, voltados à especialização (SAVIANI, 1991), são redimensionados no contexto da sociedade capitalista, pois a oferta descontínua e, na maioria dos casos, não acadêmica desses cursos tem levado à ampliação do leque de ofertas, todavia, com proposições que contemplam interesses do mercado e não do conhecimento.

\section{Procedimentos metodológicos}

Neste estudo pretendeu-se compreender o objeto de pesquisa a partir da análise documental, numa perspectiva sócio-histórica no campo da saúde e da educação e, sobretudo, através das narrativas apresentadas pelos alunos residentes do Programa estudado. A sistematização do levantamento bibliográfico e documental no campo da educação apoiou-se em autores que aprofundaram a reflexão a respeito das políticas públicas educacionais estabelecidas no Brasil, destacando-se o eixo da pós-graduação lato sensu. No campo da saúde, 
se estabeleceu o balizamento teórico considerando a implantação da política nacional de saúde para a formação profissional.

Realizada entre 2009 e 2011, a pesquisa empírica objetivou apreender a formação proposta e efetivada por um Programa da Residência Multiprofissonal implantado, no ano de 2006, por uma universidade pública, localizada no interior do estado de São Paulo, numa proposta de cogestão institucional com a Secretaria Municipal de Saúde, priorizando-se a avaliação do Residente sobre o seu processo de capacitação profissional; porém, foram também consideradas as narrativas dos outros segmentos, ou seja, dos tutores, preceptores e gestores, para o balizamento do que foi apresentado pelo Residente como questão. O Programa era financiado pelo Ministério da Saúde e estabelecia uma bolsa mensal aos estudantes para uma carga horária semanal de estudo e de formação em serviço de 60 horas, durante dois anos.

Primeiramente, foram localizados todos os segmentos envolvidos no Programa (com um total de 146 profissionais) ${ }^{3}$ e definiram-se os sujeitos ( 95 participantes a serem entrevistados), priorizando os Residentes das três primeiras turmas, cuja capacitação se deu no período de 2007 a 2011.

Tomou-se como foco para análise a avaliação dos Residentes sobre o seu processo de formação profissional nesse Programa, com a discussão dos seguintes eixos temáticos: a opção pelo Programa de Residência Multiprofissional, as expectativas geradas, a formação profissional vivenciada e os resultados alcançados.

\section{Resultados e discussão}

No primeiro eixo, que tratou das razões que levaram os entrevistados a procurar essa modalidade de formação, a maioria do grupo manifestou o descontentamento com o que experimentaram no processo de formação profissional graduada. A crítica se referia à concepção educacional dos cursos de graduação em saúde, que reduzem a educação a propostas mínimas e que têm como base apenas a formação tecnológica.

Os residentes narraram que durante a graduação o debate sobre o contexto histórico e político da saúde foi desvalorizado, na medida em que a concorrência maior era das disciplinas que simbolizam a obtenção do conhecimento técnico especializado. Dessa forma, avaliaram que o trabalho intelectual se distancia do trabalho prático e que a academia ocupa um lugar elitizado, desfavorecendo a aproximação do estudante com a realidade e necessidade dos serviços.

3 O grupo de profissionais desse Programa de Residência Multiprofissional foi composto por: 11 tutores, sendo a sua maioria docente da própria universidade; 9 preceptores, profissionais de saúde pertencentes às equipes dos serviços e com trabalho diário na unidade; 7 gestores, da universidade e da cidade, que ocuparam o cargo de pró-reitores da universidade, coordenador do Programa, secretário municipal de saúde e diretor da ABS; 43 Residentes da $1^{\mathrm{a}}$ turma e 38 na $2^{\mathrm{a}}$ e $3^{\mathrm{a}}$ turmas. 
A minha formação política, eu busquei fora, pois o curso era totalmente clínico, formador de técnicos; formei-me um bom técnico, sabendo todos os procedimentos, mas zero de formação política, zero de satisfação, zero de noção da realidade de saúde da população e zero de setor público [...] Diante da minha decepção com o curso, comecei a me envolver mais com a saúde da minha região e me interessar cada vez mais pela saúde coletiva. (SALGADO, fisioterapia).

Esse depoimento não foi um caso isolado, era recorrente, o que leva ao questionamento da dicotomia do conhecimento que tem sido produzido nos cursos de graduação, em que a fragmentação excessiva da sua aquisição e da capacidade de intervenção prática tem operado a produção dos processos de ensino-aprendizagem, na maioria das escolas. A academia, que deveria ser capaz de atender ao seu compromisso social (GOERGEN, 2006), tem favorecido a mercantilização do sistema educacional e a desregulação de um conjunto de bens sociais (SANTOS, 1995).

O segundo eixo da análise diz respeito à opinião do residente sobre a política implantada pelos Ministérios da Saúde e da Educação com esse Programa.

O grupo afirmou a assertividade dessa política de formação profissional, questionando, entretanto, a sua exequibilidade. Apontaram como distorção a forma pela qual o Programa está sendo implantado nas diversas regiões do país, uma vez que fica a critério dos gestores municipais a definição das prioridades para sua "implementação", o que cria muitas diferenças e faz com que haja menor esforço coletivo, ao menos no nível local, na luta para a efetivação da política de educação permanente. Além disso, avaliou-se que a estrutura educacional do Programa, no formato de Residência, ou seja, a não contratação de profissionais a passarem por processos formativos continuados e sim de estudantes bolsistas que devem atuar profissionalmente, corrobora para a sustentação de uma sociedade subordinada à lógica neoliberal de gestão do Estado capitalista, em que o trabalho precário é central, sendo responsável pelo efeito avassalador das limitações de perspectivas mais solidárias na construção de políticas democráticas.

Diante dessas justificativas, é necessário se assinalar o equívoco de se delegar à lógica neoliberal a culpabilidade exclusiva pelos entraves da formação profissional, o que foi feito pela maioria dos residentes. Não restam dúvidas de que os paradigmas da pós-modernidade contribuíram para o enraizamento de traços históricos fundamentais no contexto da educação brasileira. A investida contra as ideias marxistas e a intolerância dos saberes construídos ocuparam posições de poder acadêmico, principalmente depois da queda do muro de 
Berlim (1989) e do fim da União Soviética (1991), onde a onda de ataques aos "velhos esquemas interpretativos" impregnou as universidades (BITTAR, 2006).

Entretanto, há que se analisar que os traços da escravidão continuaram presentes desde a Colônia (PRADO JR., 1991), depois no Período Monárquico e na República (NAGLE, 1985), assim como nos governos populistas de Vargas e de Goulart e, posteriormente, nos governos militares a partir de 1964.

Sendo assim, é preciso levar em consideração que as ideias pós-modernistas encontraram terreno fértil numa sociedade culturalmente marcada pelo escravismo. Como resultado, as reformas no campo da educação têm sido atreladas a uma cultura conservadora que sustenta a racionalização do ensino, a prioridade na formação técnica e o modelo de formação acadêmica vinculada à formação para a produção imediata (CHAUÍ, 1981). Isto não é diferente na saúde, pois a ideia caritativa da produção de cuidado à doença e aos agravos de saúde, acompanhada do processo de autoritarismo do Estado, continua presente, apesar de alguns aspectos terem contribuído para certa socialização das políticas de saúde nos últimos anos da ditadura militar. Ao mesmo tempo em que o Estado implantava políticas de privatização e reduzia o financiamento dos serviços da saúde, instigava o fortalecimento dos movimentos sociais na luta pela reforma sanitária (COSTA, 1989), inclusive favorecendo uma importante politização da sociedade brasileira (SANFELICE, 1986). Contudo, não houve um enraizamento significativo dessa cultura depois do período da repressão, pois a transição, entre nós, se deu com mais elementos de conservação do que de transformação.

Desse modo, desde sua implantação, o SUS, enfrenta grandes dificuldades para o seu reconhecimento, apoio e para a sua efetivação mais plena, seja por parte dos gestores, em seus diferentes níveis, ou mesmo pelos profissionais e pela população (SANTOS, 2011).

As conquistas políticas e jurídicas no campo do direito à saúde e os avanços organizativos e assistenciais propiciados pela implantação do SUS não foram suficientes para equacionar os velhos e os novos problemas da atenção à saúde [...]. Dentre os problemas a equacionar ressaltamos: a crucial questão da gestão de pessoal no SUS (VASCONCELOS; PASCHE, 2012, p. 558).

Nesse quadro, têm destaque as condições vigentes de precarização do trabalhador com baixa remuneração, ausência de planos de carreiras e salários, assim como o pouco investimento em programas para a formação e capacitação profissional, gerando múltiplas contradições (PIERANTONI, 2002; CAMPOS, MACHADO, PIERANTONI, 2006). 
Todavia, não se pode negar que o Programa da Residência deve ser considerado como uma tendência para a construção de políticas de formação de recursos humanos na saúde. Em primeiro lugar, porque gerou micro rupturas na política hegemônica da formação superior em saúde, introduzindo uma modalidade que, até então, era de exclusividade da área médica. Depois, porque pretende ser uma estratégia para a implantação do SUS, o que suscita perspectivas menos pessimistas com relação ao papel do Estado em velar pelo cumprimento dessas prescrições legais.

O terceiro eixo analisado na pesquisa foi sobre a vivência do Residente na implantação do processo de estruturação desse Programa na universidade e nos serviços.

As narrativas apontaram para uma política de tutela, referindo-se que a criação do Programa se deu em um período de disputa eleitoral, com expoentes da administração universitária buscando intervir diretamente no poder executivo do município, o que levou à incorporação, na proposta de governo, da referência explícita da estruturação do sistema de saúde do município a partir da introdução do curso de graduação em medicina na universidade, algo sob sua égide e bastante almejado por importantes setores do eleitorado. Nessa condição, possibilitou-se também a submissão da proposta de criação do Programa de Residência Multiprofissional na cidade, atrelado ao propósito de reorganizar o trabalho nas unidades básicas de saúde (UBS) para viabilizar o ensino prático, ao menos em seus anos iniciais, aos alunos de medicina.

O grupo relatou, ainda, que os trabalhadores da rede pública de atenção à saúde no município não participaram desse processo e que muitos residentes, quando chegaram às unidades básicas de saúde, encontraram grande resistência da equipe, que, na maioria das vezes, conhecia pouco sobre o Programa e convivia com uma realidade de sucateamento dos equipamentos e desvalorização do trabalho profissional. Além disso, a organização dos serviços de saúde da cidade era fortemente ancorada no modelo do sistema de atenção médica supletiva, com apenas 16\% da população sendo coberta da Estratégia Saúde da Família (ESF), elemento central na ABS no Brasil.

No meu município tinha 30 Unidades de Saúde da Família (USF) com uma população de um pouco mais de 6 mil habitantes; aqui tem 15 USF com uma população de mais de 220 mil. Isso é um absurdo, como é que pode implantar a Residência nessa rede? Quando cheguei aqui, pensei que ia encontrar outra realidade (SODRÉ, enfermagem).

Nesse entrave, a avaliação da maioria do grupo foi de que a gestão utilizou mão de obra do Residente para favorecer a implantação do curso de medicina, 
mas também para oferecer assistência, no âmbito da ABS, a uma demanda reprimida na cidade, aproveitando para divulgar uma imagem ilusória de ampliação da oferta profissional especializada nas UBS e nas unidades de saúde da família (USF).

Assim, além da dificuldade estrutural, as condições reais não garantiram o processo de formação profissional e o Residente teve que fazer vários enfrentamentos.

A gente fica em dúvida se o Residente está aqui para cobrir alguns buracos da rede porque alguns ficam semanas, meses, sozinhos, tocando a unidade, cobrindo férias de funcionário, licença, e a prefeitura não tem pressa de repor os profissionais (CRUZ, enfermagem).

Outra questão apresentada diz respeito à realidade encontrada no serviço, em que a maior parte das equipes subestimou e pouco se envolveu com os residentes.

O fato das coisas irem acontecendo juntas dava muita angústia, foram os residentes que levaram o programa para os serviços, os funcionários não sabiam que ia ter residência, qual era a proposta, o que era, o que poderia ser feito, qual era a carga horária, enfim não sabiam qual era o objetivo de ter tantos profissionais no serviço (MEDEIROS, nutrição).

Alguns residentes avaliaram, também, que a falta de compromisso dos profissionais da rede com o projeto SUS poderia ser justificado pelo pouco conhecimento histórico e político da constituição da atenção à saúde no Brasil. Essa situação gerou resistências à mudança de modelo e o descomprometimento com o Programa, que, por sua vez, equivocadamente, tomou para si a responsabilidade de (re) organizar as unidades vinculadas à ESF. Além disso, a Residência ocupou um lugar de disputa nos serviços, seja com os estagiários dos diferentes cursos de graduação que também ocupavam o mesmo espaço físico, insuficiente, ou mesmo entre os funcionários que se sentiam incomodados, desconsiderados, invadidos e/ou ameaçados.

As narrativas apontaram ainda a crítica aos tutores justificando que, em diversas situações de tensão, eles se eximiram da sua responsabilidade quanto à orientação e não participaram do debate político.

A universidade usa o serviço apenas como campo de aprendizagem, mas não tem um posicionamento político forte, não é parceira da Residência. Estamos num curso de formação que não é apenas do reconhecimento no campo da tecnologia, mas é uma formação política, tem que haver posicionamento político. A gente faz discussões não só em tese, discussões em 
todos os espaços, no nosso próprio grupo, na unidade, no território, em outros equipamentos sociais e isso tudo precisa ser ouvido e talvez, mais bem direcionado. Não pode ficar esgotado no próprio grupo de residentes (SAVIO, educação física).

A avaliação sobre o envolvimento dos profissionais, considerado pequeno e insuficiente (tanto da universidade, quanto do serviço), também foi direcionado ao próprio Residente, pois nem todos tinham interesse e, nem mesmo, compreensão no/do seu protagonismo; não se envolveram com a política do SUS e com a efetivação da proposta.

Face às narrativas e aos documentos analisados, considera-se que, embora os gestores tenham apostado na estratégia de capacitação e gestão de pessoal, o processo de formação ficou subjugado ao domínio de interesses alheios à transformação do status quo, ainda que restrita à ABS, e reforçou as contradições às quais os trabalhadores da rede de atenção nos serviços estavam submetidos.

$\mathrm{Na}$ análise sobre o sistema de saúde do município, verificou-se que dos 388 serviços de saúde, apenas 42 eram públicos (IBGE, 2005), o que representa a situação predominante do modelo de privatização. Ainda, pressupondo que a intenção dos gestores tenha sido a de favorecer um outro modo de produção de saúde, através da implantação do curso de medicina e do Programa de Residência Multiprofissional, a operacionalização desses projetos tinha razões instrumentais no bojo da disputa eleitoral. Assim, os trabalhadores da saúde ficaram submetidos à implantação de uma política imposta pelos gestores e, embora a ESF tenha sido adotada como eixo estruturante da rede de ABS no município, excluiu-se a participação de seus profissionais, com a predominância nos serviços daquilo que é considerado uma equipe mínima de médicos, enfermeiros e agentes comunitários de saúde, sem a contratação direta dos demais técnicos.

A mudança de modelo de atenção em saúde particulariza-se na análise do modo de produção de suas ações, bem como na forma pela qual são organizadas as instituições responsáveis por essa produção. Ademais, o trabalho na saúde é um campo de ação do trabalho vivo, de gerenciamento das relações e da construção cotidiana de vínculos e compromissos entre gestores, trabalhadores e usuários (CECÍLIO, 1994; MERHY, 2005; CAMPOS, 2007). Nesse contexto, pareceu evidente que a materialização deste Programa foi assentada num modelo de precarização de recursos, com um baixo desempenho dos processos de gestão.

O quarto eixo de análise foi sobre a avaliação desse modelo de formação profissional, a ser abordada pelos entrevistados em duas perspectivas: das atividades de treinamento em serviço e das atividades de ensino. 
A maioria do grupo apontou a importância dos eixos norteadores do processo ensino-aprendizagem previsto pelo Programa, principalmente do cenário de educação em serviço, da concepção ampliada de saúde e da política de educação permanente. Afirmaram que a concepção voltada à aprendizagem a partir do desenvolvimento da prática profissional possibilitou o reconhecimento da realidade do serviço.

Todavia, no que se refere à avaliação da aprendizagem, todos os entrevistados criticaram a metodologia de ensino adotada pelo Programa, justificando que o fato da aprendizagem ter como cenário a educação em serviço, não garante, necessariamente, o conhecimento; a construção desse conhecimento e a formação advinda, para o Residente, ficou sob sua responsabilidade. Ainda, consideraram as políticas impositivas e com atravessamento nas práticas pedagógicas pelas metodologias ativas de ensino-aprendizagem, condicionantes do Programa para a formação profissional em saúde. Essa condição dificultou a atuação da maioria dos orientadores, como também não estimulou a produção científica e a participação mais efetiva dos professores da universidade para a formação e gestão de pessoal no campo da saúde.

$\mathrm{Na}$ exigência da formação se dar através desse modelo metodológico, as críticas mais contundentes foram direcionadas aos orientadores (tutores e preceptores), por não terem o domínio das metodologias.

[...] a utilização delas se deu de forma equivocada, apenas com uma roupagem construtivista (Salgado, fisioterapia).

A formação em serviço é uma das experiências mais válidas, só que tem que garantir o espaço de reflexão da prática, não adianta jogar a gente no serviço, numa unidade superdesestruturada e achar que você vai aprender (MEDEIROS, nutrição).

A exceção apontada pelos Residentes das duas primeiras turmas foi ao grupo de professores do curso de graduação em medicina da universidade, que se destacou, principalmente por já ter experiência de trabalho no campo da saúde pública, especificamente com comunidades da periferia.

Tive orientadores mais coerentes que faziam um paralelo da academia e a prática do serviço junto com os preceptores, questionavam, in loco, eram os tutores da medicina, que têm proximidade e militância no SUS e fazem uma crítica a esse método. Eles me ajudaram muito porque na graduação eu fugia da clínica, não conseguia ver muita lógica no que eu fazia enquanto dentista. Achava que era uma atuação muito limitada, muito técnica e pouco resolutiva porque a maioria dos dentistas não entende 
a cárie como uma doença, mas como um buraco que precisa ser tratado $e$, se você ensinar um macaco, ele vai aprender a fazer. Isso para mim era muito dificil de aceitar. Hoje eu consigo ver de outro jeito, a minha consulta é mais demorada e não se resume à cadeira do paciente, e isso mudou com a residência (FRAGELLI, odontologia).

Nesse contexto, ainda referiram a falta de capacitação dos profissionais do serviço, pois a maioria dos trabalhadores exercia uma prática centrada na doença e organizava suas ações especialmente para a assistência da demanda espontânea. Além disso, tinham pouca experiência com equipe multiprofissional, o que implicava no desconhecimento sobre a qualidade e a eficiência dos resultados, principalmente nas áreas de Terapia Ocupacional, Fisioterapia, Nutrição, Farmácia e Serviço Social. No município, essas profissões somente estavam contempladas como especialidade, ainda assim de maneira muito reduzida em termos numéricos na rede, justificando a lógica do encaminhamento para os serviços de atenção secundária, com "filas" bastante significativas para $\mathrm{o}$ atendimento.

Também relataram um processo de descuido na gestão do Programa, no sentido da organização das turmas e do conteúdo curricular. Somente as duas primeiras turmas conseguiram realizar diversas ações de forma coletiva; a partir da $3^{\text {a }}$ turma, os grupos de residentes foram subdivididos; a avaliação do grupo é de que a separação das turmas foi uma estratégia da gestão para dificultar as críticas ao Programa que vinham sendo produzidas pelo coletivo.

A respeito do conteúdo curricular, os residentes julgaram que não existiu um esclarecimento sobre o conteúdo básico proposto, deixando a critério de cada Residente a composição das temáticas para a aprendizagem. A coordenação do Programa teria apenas exibido as atividades e o cenário de ensino-aprendizagem-trabalho, ressaltando, discursivamente, o seu projeto político pedagógico como sendo uma inovação na organização curricular. Cada uma das turmas criou, a cada ano, suas práticas, independentemente do trabalho já construído, como se fosse um "começar de novo", já que nem a gestão municipal, nem a universidade, e nem mesmo as equipes da rede de saúde, direcionaram o processo. Isso era imputado às ditas metodologias ativas inovadoras.

O estabelecimento do sistema de avaliação formativa foi igualmente questionado pela maioria, fosse pela ausência da devolutiva dos resultados ou mesmo pelos equívocos apresentados pelos orientadores no desempenho dessa tarefa. Os tutores instituíram momentos formais de avaliação, os quais foram transformados em provas teóricas, e os preceptores, em grande parte 
das vezes, "subjetivaram" a avaliação, pois também apresentavam dificuldades para desempenhar as competências necessárias a esse processo. Depois, o uso do portfólio ${ }^{4}$ e a exigência da monografia, utilizados como instrumentos para avaliação do Residente, pouco contribuíram com o processo de ensino-aprendizagem. O portfólio ficou caracterizado como uma simples pasta de anotações e registros de trabalhos temáticos. A monografia, embora entendida como uma atividade importante, não viabilizou a pesquisa, tanto por conta da escassez de tempo para isso, sem horários estabelecidos na grade curricular para o Residente e para o orientador, quanto pela dificuldade em adequar os projetos às linhas de pesquisa do orientador.

A partir dessas narrativas é possível compreender que a política de formação e desenvolvimento de profissionais para a saúde passou a ser uma política da ABS no SUS, que se pretendia uma Rede-Escola (BRASIL, 2007), porém, ao impor um determinado referencial pedagógico como o mais adequado para a formação de recursos humanos na saúde, determinou um único modelo de ensino e, certamente, buscou introduzir uma única perspectiva para a obtenção do conhecimento técnico. Como resultado, a preocupação política em criar um programa de formação profissional com uma concepção pedagógica que enfrentasse os problemas percebidos como advindos do modelo tradicional de educação, acabou por desconsiderar a transmissão do conhecimento clássico acumulado historicamente pela humanidade (FERREIRA JUNIOR, 2008) e, assim, correndo o risco de produzir o desprezo com relação a outros conhecimentos já produzidos e estruturados; como nos sugere Bittar (2006, p. 3), "podemos jogar fora a criança com a água do banho".

As narrativas apontaram para a apreciação das aulas expositivas, a crítica da falta de orientação para as "buscas" (busca ativa), a indefinição dos temas, a necessidade de regulamentar agendas, cronogramas e atividades, a pouca experiência profissional do Residente para contribuir com a gestão da unidade e a própria crítica ao grupo de orientadores. Dessa maneira, pareceu haver a reinvindicação de uma educação baseada no saber metódico, estabelecido e organizado, com o professor produzindo a aula e materializando-a na forma de transmissão e de socialização de conhecimentos sistematizados. Ou seja, a necessidade de um trabalho educativo em que se pressupõe a possibilidade do professor apresentar ao aluno à identificação dos elementos culturais que precisam ser conhecidos, assimilados e preservados (DUARTE, 2008; SAVIANI, 1991).

4 Dossiê organizado pelo Residente com o registro das experiências, contendo o material pesquisado, documentos, trabalhos e relatos que fazem parte da formação profissional. 
Nessa perspectiva, não há dúvidas sobre a importância da academia para a capacitação profissional, não obstante, na medida em que se impõe uma separação mecânica entre a formação propedêutica e a formação profissional, pode se produzir uma concepção elitista da educação, fazendo prevalecer a dicotomia entre saberes e práticas profissionais.

O quinto eixo analisado se referiu ao alcance e à permanência dessa proposição política para a formação pós-graduada em saúde.

As narrativas apontaram a ineficácia do Programa, principalmente porque não favoreceu a inserção qualificada desses profissionais na rede municipal de saúde, uma vez que nos poucos concursos realizados pela gestão do município, apenas uma área profissional foi priorizada (enfermagem). Na ocasião, a justificativa dada pelo executivo foi a escassez de recursos financeiros para tentar compor as equipes de saúde nas Unidades. Sendo assim, os Residentes concluíram que o município vai dar continuidade a essa proposição, enquanto houver investimento do governo federal, na medida em que julgam haver um desinteresse real em valorizar o profissional da rede, mantendo-se a escassez de recursos humanos.

A falta de valorização da Residência é evidente nesta gestão porque o governo investe dois anos em mim e depois me abandona, eu pensei que o SUS me quisesse, que a gestão local ou [...] a estadual me quisesse. Então, a gente fica dois anos, mas nem o serviço incorpora o residente, nem a academia (PAVAN, enfermagem).

Ainda, consideraram que a falta de regulação, acompanhamento e avaliação dos resultados do Programa nas três esferas de governo comprometem o alcance e a continuidade dessa política. Além disso, há muitas controvérsias entre os próprios representantes da gestão sobre a necessidade desse modelo de capacitação, inclusive por conta do custo financeiro.

Nesse mesmo eixo de debate, as narrativas dos residentes apontam que a universidade apenas serviu de cenário para a execução do Programa, pois, na sua prática, não fortaleceu o processo de formação do profissional para o SUS, uma vez que, não obstante o Programa ter previsto uma formação teórico-conceitual e metodológica que potencializasse competências para a integralidade das ações em saúde, pouco se explorou os saberes produzidos pela própria universidade; embora, os gestores da academia atestem a importância do Programa e reconheçam ser este um dos papéis da IES. Já, os tutores justificaram a dificuldade organizacional da universidade em deslocar uma parte dos docentes para desempenhar essa nova tarefa. 
Com esses resultados advindos da análise dos depoimentos, é possível afirmar que o Programa se conformou dentro da ordem social colocada para a atenção à saúde, restritiva com relação a provê-la com qualidade como um direito de todos e um dever do Estado. Os gestores do município argumentaram que não é possível oferecer boa assistência com o que se tem de recursos, lançando mão da justificativa mundialmente utilizada pelos dirigentes dos serviços de saúde, onde a focalização de recursos deve ser dirigida a grupos populacionais excluídos e, na maioria das vezes, localizados nas regiões mais pobres das cidades, com base nas ações de atenção primária em saúde e, ainda assim, comprometidas com o barateamento de custos e com a baixa complexidade tecnológica (SANTOS, 2011). Nesse modelo de gestão, os trabalhadores da saúde enfrentam a precariedade dos arranjos organizacionais.

A academia, por sua vez, demonstra grande dificuldade para a incorporação efetiva dessa política; ainda que os recursos financeiros e humanos não sejam um obstáculo tão potente quanto nos serviços, o fazer acadêmico parece ter outras prioridades e, até mesmo, outras funções que não a produção de assistência, mesmo que por meio da tutoria dos residentes. Neste estudo, a maioria dos profissionais envolvidos com o Programa expressou essa dimensão.

\section{Conclusão}

As ideias pedagógicas e políticas adotadas pelo Estado brasileiro têm reforçado o modelo "produtivista" da educação, pois, uma vez que não se prioriza uma cultura de educação básica, o acesso ao ensino superior tem se dado com grandes carências acadêmicas e as IES, em sua maior parte, sustentam os interesses do mercado.

Atualmente, ao mesmo tempo em que vivemos o incentivo político para a formação de recursos humanos para o SUS, o que tem sido colocado como estratégia para sua reorganização numa direção mais alinhada aos preceitos constitucionais, continuamos a assistir várias contradições.

É bem verdade que a herança de uma cultura escravista numa sociedade fundada no primado da propriedade privada dos meios de produção não poderia ter como premissa a proposição de políticas sociais, porém, a conquista do Sistema Único de Saúde é um elemento que alargou esse horizonte e que tem tensionado o status quo; com o SUS, a maior parte dos brasileiros foi incluída no universo da cidadania no âmbito do cuidado à saúde e, apesar dos pesares, não tanto quanto o necessário, temos avançado desde então (MENDES, 2001; LOPES, 2001).

Todavia o poder conservador no Brasil impõe uma política de restrição dos gastos públicos e de expansão do setor suplementar em saúde (LUZ, 1994), 
produzindo o "subfinanciamento" e a "precarização" da gestão de recursos (SANTOS, 2008, p. 434).

Assim, se por um lado o SUS trouxe a universalidade da atenção ao sistema de saúde, por outro, não garantiu a melhoria na qualidade dos serviços na mesma velocidade em que se deu a ampliação do acesso, levando à fuga para o sistema privado de uma parcela da população dos setores médios e de trabalhadores qualificados, num processo de "universalização excludente" (FAVERET; OLIVEIRA, 1989), pois os pobres só têm o SUS, enquanto os usuários dos outros sistemas podem utilizar, também, o sistema público. Além disso, a precariedade das condições de trabalho dos profissionais de saúde gerou um distanciamento destes em relação ao projeto SUS, que em grande parte das vezes tem sido banalizado (FLEURY, 2011).

Contudo, são essas mesmas condições que determinam a relevância da defesa do interesse público na saúde e da necessidade de se priorizar políticas para a efetivação do sistema, suscitando perspectivas otimistas sobre a possibilidade de qualificação dos trabalhadores. O Programa de Residência Multiprofissional tem sido apresentado como estratégia para atuar nesse "lócus", porém, é preciso que se analise a que custos o Programa tem se dado.

Neste trabalho, conclui-se que o poder indutor das políticas públicas federais para a capacitação de recursos humanos para o SUS pouco contribuiu para o enfrentamento das contradições historicamente constituídas no campo da educação e da saúde no Brasil, sendo esse pouco fortemente vinculado à produção apenas de um discurso, sem chances efetivas de enraizamento.

Em primeiro lugar porque o Programa restringiu-se à estruturação da rede de serviços públicos por meio da oferta de um campo de trabalho precarizado para os profissionais da saúde.

Depois, a formação do profissional para o SUS ficou submetida a um modelo de saúde que prioriza a excelência privada e, sendo assim, a Residência foi implantada com a simplificação de recursos municipais, além do pouco equilíbrio entre o serviço e a academia, o que é recorrente na produção e na aquisição do conhecimento.

Finalmente, a indução política das intercessões promovidas pela educação na saúde, com base em pressupostos do processo ensino-aprendizagem tidos como inovadores, ativos e em tecnologias construtivistas, não garantiu uma interlocução entre formação, gestão, atenção e participação dos profissionais.

Desta forma, o Programa apresentado também se operacionalizou na lógica do mercado: da contenção de custos e da restrição ao acesso, seguindo o caminho das recomendações feitas pelo Banco Mundial, que aconselha a ampliação das escolas privadas, dos planos e seguros de saúde para a maio- 
ria da população, restringindo os serviços públicos na modalidade básica à população pobre.

Assim, a formulação de uma práxis social capaz de superar as condições que vêm nos submetendo a graves desigualdades socioeconômicas foi substituída por essas recomendações; de fato, as políticas sociais no Brasil encontram-se permanentemente ameaçadas, apesar de atadas a um discurso recorrente da necessidade de investimentos na saúde, educação, previdência social e em outros setores aos quais se impõe a luta pela consecução dos direitos sociais advindos da cidadania.

\section{Referências}

BARBOSA, Nelson Bezerra. Regulação do trabalho no contexto das novas relações público versus privado na saúde. Ciência \& Saúde Coletiva, Rio de Janeiro, v. 15, n. 5, 2010.

BITTAR, Marisa. O estado da arte em História da Educação brasileira após 1985: um campo em disputa. Campinas: HISTEDBR-DEFHE/FE/ UNICAMP, 2006. Disponível em: <http:/www.histedbr.fae.unicamp.br/ navegando/artigos_frames/artigo_078.html>. Acesso em: 10 mar. 2009.

. Universidade, pesquisa educacional e educação básica. In: BITTAR, Marisa; LOPES, Roseli Esquerdo (Orgs.). Estudos em fundamentos da educação. São Carlos: Pedro \& João Editores, 2007. p. 21 - 49.

BRASIL. Ministério da Saúde, Ministério da Educação. Portaria interministerial № 45/2007 de 12 de janeiro de 2007. Diário Oficial da União, Brasília, DF, Seção 1, p. 28-9, 2007.

. Ministério da Saúde. Departamento de Gestão da Educação na Saúde. Secretaria de Gestão do Trabalho e da Educação na Saúde. Manual Técnico do Departamento de Gestão da Educação na Saúde. Brasília: MS, 2006.

. Ministério da Saúde. Ministério da Educação. Portaria Interministerial № 2.117/05. Diário Oficial da União, Brasília, DF, 04 nov. 2005 .

Conselho Nacional de Saúde. Resolução № 287, 08 de outubro de 1998. Brasília, 1998. Disponível em: <http://www.crefrs.org.br/legislacao/ pdf/resol_cns_287_1998.pdf>. Acesso em: 12 abr. 2009.

CAMPOS, Francisco Eduardo; MACHADO, Maria Helena; PIERANTONI, Célia Regina (Org.). Cadernos RH Saúde, Brasília, v. 3, n. 1, 2006. 
CAMPOS, Gastão Wagner de Souza. Clínica e saúde coletiva compartilhadas: teoria paidéia e reformulação ampliada do trabalho em saúde. In: CAMPOS, Gastão Wagner de Sousa et al (Org.). Tratado de Saúde Coletiva. São Paulo: Hucitec, 2007. p. 41-80.

CECILIO, Luiz Carlos de Oliveira. Inventando a mudança na saúde. São Paulo: Hucitec, 1994.

CHAUÍ, Marilena de Souza. Cultura e democracia: o discurso competente e outras falas. São Paulo: Moderna, 1981.

COSTA, Nilson do Rosário. Transição e movimentos sociais: contribuição ao debate da reforma sanitária. In: NAJAR, Alberto Lopes; COSTA, Nilson do Rosário (Org.). Demandas populares e políticas públicas de saúde. Petrópolis: Vozes/Abrasco, v. 1, p. 45-65, 1989.

DUARTE, Newton. Sociedade do conhecimento ou sociedade das ilusões? Quatro ensaios críticos-dialéticos em filosofia da educação. Campinas: Autores Associados, 2008.

FAVERET FILHO, Paulo; OLIVEIRA, Pedro Jorge de. A universalização excludente: reflexões sobre as tendências do Sistema de Saúde. Rio de Janeiro: UFRJ/IEI, 1989.

FERREIRA JUNIOR, Amarilio. A educação na perspectiva marxista: uma abordagem baseada em Marx e Gramsci. Interface: comunicação, saúde, educação, Botucatu, SP, v. 12, n. 26, p. 635-646, jul./set., 2008.

FIGUEIREDO, Gil Vicente Reis de. Educação universal de qualidade: um projeto para o Brasil. Brasília: Proifes, 2010.

FLEURY, Sonia. Defesa intransigente do interesse público na saúde. In: SIMPÓSIO DE POLÍTICA E SAÚDE, 2., 2011, Brasília. Brasília: CEBES, julho 2011.

GOERGEN, Pedro. Universidade e compromisso social. Brasília: Instituto Nacional de Estudos e Pesquisas Anísio Teixeira-Inep/MEC, 2006. p. 16-95

IBGE - INSTITUTO BRASILEIRO DE GEOGRAFIA E ESTATÍSTICAIBGE/2005. Disponível em: <http://www.ibge:MinistériodaSaúde.gov.br/home/ estatistica/populacao/trabalhoerendimento/pnad2005>. Acesso em: 5 fev. 2013.

LOPES, Roseli Esquerdo. Políticas de saúde no Brasil: construções, contradições e avanços. Revista de Terapia Ocupacional da Universidade de São Paulo, São Paulo, v. 12, n. 1/3, p. 23-33, jan./dez., 2001. 
LUZ, Madel Therezinha. As conferências nacionais de saúde e as políticas de saúde da década de 80. In: GUIMARÂES, R.; TAVARES, R. Saúde e sociedade no Brasil: anos 80. Rio de Janeiro: Relume Dumará, 1994.

MARX, Karl. O capital - crítica da economia política. São Paulo: Abril Cultural. Livro primeiro: processo de produção do capital, 1983.

MACHADO, Maria Helena. Trabalho e emprego em saúde. In: GIOVANELLA, Lígia (Org.). Políticas e sistema de saúde no Brasil. Rio de Janeiro: Fiocruz, 2010. p. 309-332.

MENDES, Eugênio Villaça. Os grandes dilemas do SUS. Salvador: Casa da Qualidade Editora, 2001. T. I

MERHY, Emerson Elias. Saúde: a cartografia do trabalho vivo. São Paulo: Hucitec, 2005.

NAGLE, Jorge. A educação na Primeira República. In: HOLANDA, Sérgio Buarque de. História geral da civilização brasileira. São Paulo: Difel, 1885. T III, Livro 3, p. 259-291.

NOSELLA, Paolo; BUFFA, Ester. Schola mater: a antiga Escola Normal de São Carlos, 1911-1933. São Carlos: EdUSFCar, 2002.

. Artes liberais a artes mecânicas: a difícil integração. ANPEd, 1998.

PIERANTONI, Célia Regina. Recursos humanos e gerência no SUS. In: NEGRI, Barjas; FARIA, Regina; VIANA, Ana Luiza D’Avila (Org.).

Recursos humanos em saúde: política, desenvolvimento e mercado de trabalho. Campinas: Ed. Unicamp, 2002. p. 221-256.

PRADO JR., Caio. Evolução política do Brasil: colônia e império. São Paulo: Brasiliense, 1991.

ROSA, Soraya Diniz. Tecendo os fios entre educação e saúde: a formação profissional na Residência Multiprofissional em Saúde. 2012. 219 p. Tese (Doutorado) - Universidade Federal de São Carlos-UFSCar, São Carlos, 2012.

SANFELICE, José Luis. Movimento estudantil: a UNE na resistência ao golpe de 64. São Paulo: Cortez, 1986. 
SANTOS, Boaventura de Souza. Pela mão de Alice: o social e o político na pós-modernidade. São Paulo: Cortez, 1995.

SANTOS, Nelson Rodrigues dos. O SUS e a reforma sanitária:

possibilidades e potencialidades. In: SIMPÓSIO DE POLÍTICA E SAÚDE, 2., 2011, Brasília. Brasília: CEBES, julho 2011.

. Desenvolvimento do SUS, rumos estratégicos e estratégias para visualização dos rumos. Revista Ciência e Saúde Coletiva, Rio de Janeiro, v. 12, n. 2, p. 429-435, mar./abr., 2008.

SAVIANI, Dermeval. Desafios da construção de um sistema nacional articulado de educação. Trabalho, Educação e Saúde, Rio de Janeiro, v. 6, n. 2, p. 213-231, jul./out. 2008.

. Transformações do capitalismo, do mundo do trabalho e da educação. In: LOMBARDI, José Claudinei; SAVIANI, Dermeval; SANFELICE, José Luís (Orgs.). Capitalismo, trabalho e educação. Campinas: Autores Associados, HISTEDBR, 2002. p. 13-24.

. Concepção de dissertação de mestrado centrada na ideia de monografia de base. Revista do Conselho de Reitores das Universidades Brasileiras, Brasília, v. 13, n. 27, p. 159-168, jul./dez.1991.

VASCONCELOS, Cipriano Maia de; PASCHE, Dário Frederico. O Sistema Único de Saúde. In: CAMPOS, Gastão Wagner de Souza et al. Tratado de saúde coletiva. São Paulo: Hucitec, 2006. p. 531-562.

Soraya Diniz Rosa - Universidade de Sorocaba Sorocaba | SP | Brasil. Contato: soraya.rosa@prof.uniso.br

Roseli Esquerdo Lopes - Universidade Federal de São Carlos Sorocaba | SP | Brasil. Contato: relopes@ufscar.br

Artigo recebido em 8 de março de 2014 e aprovado em 2 de julho de 2014. 


\section{Normas para colaborações}

A AVALIAÇÃO aceita para publicação artigos inéditos de autores brasileiros e estrangeiros que tratem de educação, resultantes de trabalhos acadêmicos que são produzidos, sobretudo nos meios universitários e que contribuem para o desenvolvimento das teorias e práticas de avaliação e os debates gerais sobre educação superior no Brasil e nos demais países ibero-americanos. Os artigos são publicados na língua original dos seus respectivos autores, de preferência em português e espanhol e não devem ultrapassar 20 páginas.

A publicação de artigos está condicionada a pareceres de membros do Conselho Editorial ou de colaboradores ad hoc. A seleção de artigos para publicação toma como critérios básicos sua contribuição à educação e à linha editorial da Avaliação, a originalidade do tema ou do tratamento dado ao mesmo. Eventuais modificações de estrutura ou de conteúdo, sugeridas pelos pareceristas ou pela Comissão Editorial, só serão incorporadas mediante concordância dos autores. Os revisores dos originais poderão ajustá-los aos padrões da convenção escrita de modo a contribuir para a adequação do texto ao periódico.

Todos os artigos devem conter resumo (em português) e abstract (em inglês), com indicação de pelo menos três palavras-chave e key words.

$\mathrm{O}$ autor deve também fornecer dados relativos a sua maior titulação, instituição e área em que atua, bem como indicar o endereço eletrônico e o endereço completo, para correspondência.

Os originais poderão ser encaminhados à AVALIAÇÃO por meio do sistema SciELO. Orientações quanto os procedimentos constam no site: <http://www.scielo.br/ revistas/aval/pinstruc.htm>. O envio de qualquer colaboração implica automaticamente a cessão integral dos direitos autorais para publicação e disponibilização on-line à AVALIAÇÃO: Revista da Avaliação da Educação Superior. O autor terá direito a dois exemplares do periódico no qual foi publicado seu artigo. Dúvidas e sugestões devem ser enviadas para revistaavaliacao@ gmail.com.

As submissões devem ser realizadas on-line no endereço: 


\section{Orientações para formatação e normalização}

O texto deve ser digitado em fonte Times New Roman, corpo 12, com 1,5, ter no máximo 20 páginas. O uso do recurso itálico, no corpo do texto, deve ser utilizado somente para palavras estrangeiras. Para apresentação dos elementos que constituem o artigo utilizar as normas da ABNT em vigor. Sugerimos não acrescentar destaques, grifos e etc. em citações diretas, pois são informações ou detalhes que podem desaparecer após a normalização e/ou diagramação final.

Utilizar negrito e maiúsculas para o título principal, e negrito e maiúsculas e minúsculas nos subtítulos das seções.

As menções a autores, no correr do texto, devem subordinar-se à forma (AUTOR, data) ou (AUTOR, data, p.), como nos exemplos: (SILVA, 1989) ou (SILVA, 1989, p. 95). Diferentes títulos do mesmo autor, publicados no mesmo ano, deverão ser diferenciados adicionando-se uma letra depois da data, por exemplo: (GARCIA, 1995a), (GARCIA, 1995b) etc.

\section{Notas de rodapé}

Devem restringir-se a comentários e observações pessoais, destinando-se a prestar esclarecimento ou tecer considerações. Deverão ser numeradas e apresentadas ao pé da página, em corpo 10.

\section{Tabelas, Quadros e Figuras}

Devem estar inseridas em seu local no texto e devem ser enviadas em arquivos separados do arquivo do texto. As tabelas devem estar necessariamente em formato de texto, não sendo aceitas em formato de imagem. Todos estes elementos deverão estar totalmente legíveis, sem manchas nem rasuras. As figuras, gráficos ou quadros devem estar em alta resolução - 600 dpi (pixels/ polegada), com largura máxima de $12 \mathrm{~cm}$ e com altura máxima de $17 \mathrm{~cm}$.

\section{Citações:}

Citação direta: transcrição textual de parte da obra do autor consultado. As citações curtas (até 3 linhas) são inseridas no texto, entre aspas. Citações longas (mais de 3 linhas) devem constituir parágrafo independente, digitados em espaço simples e recuados a 2,5 $\mathrm{cm}$ da margem esquerda, na mesma fonte, tamanho 10, sem aspas. Supressão de texto no interior das citações devem ser colocados entre colchetes [...]. A norma indica $4 \mathrm{~cm}$ de recuo, porém optamos por usar $2,5 \mathrm{~cm}$ em razão do tamanho da página do periódico. Toda citação direta deve estar seguida do sobrenome do autor em letras maiúsculas, ano de publicação, número de página, separados por vírgula, entre parênteses. 


\section{Ex.: de citação direta com até 3 linhas}

Tanto a sociedade quanto a realidade são dinâmicas e concretamente definidas, assim, a história constitui-se num processo dinâmico e transformador na medida em que se torna "o eixo da explicação e compreensão científicas e tem na ação uma das principais categorias epistemológicas" (FAZENDA, 1997, p. 106).

\section{Ex.: de citação direta com mais de 3 linhas}

Michel Freitag (1995, p. 57) adverte que:

Mille informations ponctuelles ne valent pas une connaissance, mille decisions ne font pas un seul jugement synthétique, mille sondages ne donnent pas la prévisibilité d'une seule loi, mille probabilités ne conferment pas la certitude d'un seul principe, mille descriptions ne font pas un unique concept.

Citação indireta: texto baseado na obra do autor consultado.

Nas citações indiretas deve-se indicar sobrenome do autor e data de publicação. Ex.:

Como diz Basbaum (1978), a filosofia tem sentido [...]

\section{Referências:}

Devem conter exclusivamente os autores e textos citados no trabalho e ser apresentadas ao final do texto, em ordem alfabética, títulos de livros e periódicos devem ser apresentados em negrito, são alinhadas somente à esquerda obedecendo às normas atualizadas da ABNT.

Observa-se que as bibliotecárias das Universidades estão aptas a oferecer orientações relativas ao uso correto das mesmas.

Exemplos:

-Livro:

MEKSENAS, Paulo. Aprendendo sociologia: a paixão de conhecer a vida. São Paulo: Loyola, 1991.

\section{-Capítulo de livro:}

DEMARTINI, Zeila de Brito; ANTUNES, Fátima Ferreira. Magistério primário: profissão feminina, carreira masculina. In: CAMPOS, Maria Christina S. S.; SILVA, Vera Lúcia Gaspar da. (Orgs.). Feminilização do magistério: vestígios do passado que marcam o presente. Bragança Paulista: EDUSF, 2002. p. 69-94. 
- Artigo de periódico:

DIAS SOBRINHO, José. Sobre reformas e transformações da educação superior. QUAESTIO: Revista de Estudos de Educação, Sorocaba, SP, v.7, n.1, p. 9-21, maio, 2005.

\section{- Tese:}

SILVA, Paulo Celso da. Como anjos caídos... mensageiras em espaços de flexibilidade e redes: uma experiência geográfica. 1999.140 p. Tese (Doutorado) - Universidade de São Paulo, São Paulo, 1999.

\section{- Documento digital (on-line):}

HISSA, Hélio Barbosa. Distritos industriais (ou clusters) como estratégia de desenvolvimento econômico local para o Brasil. Economianet, 2003. Disponível em: <http://www.economiabr.net.br>. Acesso em: 1 jun. 2005.

\section{Normas da ABNT}

NBR 6022, 2003 - Informação e documentação. Artigo em publicação periódica científica impressa. Apresentação;

NBR 6023, 2002 - Informação e documentação - Referências - Elaboração; NBR 6024, 2003 - Informação e documentação - Numeração progressiva das seções de um documento escrito - Apresentação;

NBR 6028, 2003 - Informação e documentação - Resumos - Apresentação; NBR 10520, 2002 - Informação e documentação - Citações em documentos - Apresentação;

IBGE. Normas de apresentação tabular. 3.ed. Rio de Janeiro, 1993.

\section{Submissão de artigos:}

Os autores devem submeter seus artigos on-line ao endereço: http://submission.scielo.br/index.php/aval

O autor terá direito a dois exemplares do periódico no qual foi publicado seu artigo. Os revisores dos originais poderão ajustá-los aos padrões da convenção escrita de modo a contribuir para a adequação do texto ao periódico. 